\title{
IN VITRO DIFFERENTIATION POTENTIAL OF ISOLATED DENTAL PULP STEM CELLS
}

\author{
Marwa Sameer Moussa*, Shereen Hafez ${ }^{* *}$ and Dina Sabry***
}

\begin{abstract}
Objective: The aim of the present study is to isolate and characterize human dental pulp stem cells (DPSCs).Surface markers expression utilizing surface markers for flow cytometry. The odontogenic differentiation of DPSCs was assessed.

Material and methods: dental pulp tissuses were collected from impacted third molars. samples were treated with collagenase before centrifugation to allow release of the cells. Cells were cultured in complete culture medium for 12-14 days. After reaching confluence, the isolated cells were characterized by flow cytometry using CD105 and CD45. The cells were induced for odontogenic differentiation by placing the cells in odontogenic induction media for 14 days. Odontogenic differentiation was evaluated by Alizarin Red stain and by the expressions of dentine sialo phospho protein (DSPP), dentin matrix protein-1 (DMP-1) and alkaline phosphatase (ALP) activity, which were assessed by RT-PCR.
\end{abstract}

Results: The results showed that successful isolation of stem cells from human dental pulp was achieved. Cells were successfully sub-cultured and expanded up to the third passage. A flow cytometric analysis was done after stem cells isolation. Isolated DPSCs were identified by positive expression of CD105 and negative expression of hematopoietic marker C. The results showed that differentiatiationed odontoblastic like cells from DPSCs induced by odontogenic medium were stained by Alizarin Red at days 7 and 14. RT-PCR results indicated that all cultured cells efficiently differentiate into dentin forming cells and expressed specific DSPP, DMP1 and ALP genes at days 7 and 14.

Conclusion: DPSCs can be a possible source of stable differentiated odontoblastic cells. Their ability of inducing hard tissue formation offer an alternative method to save teeth with compromised structural integrity.

KEY WORDS: Dental pulp stem cells (DPSCs), flow cytometry, odontogenic differention, DSPP, ALP, DMP1.

* Lecturer of Oral Biology, Department of Oral Biology, Faculty of Oral and Dental Medicine, Cairo University.

** Lecturer of Operative, Department of Conservative Dentistry, Faculty of Oral and Dental Medicine, Cairo University.

*** Professor of Medical Biochemistry and Molecular Biology, Department of Medical biochemistry and Molecular

Biology, Faculty of medicine, Cairo University. 


\section{INTRODUCTION}

The ideal restoration of lost tissues is best achieved by the same natural healthy tissue in order to maintain mechanical stability and function.Stem cells are the most important cells for regenerative medicine $^{(1)}$.

Determination of the regenerative and differentional potential of stem cells will form the foundation for development of new clinical treatment modalities. Different types of post-natal mesenchymal stem cells have been used for the purpose of regeneration of the dentin-pulp complex and tissue engineering of dental tissues either from dental origin (e.g dental pulp stem cell) or from non-dental origin (e.g Bone marrow) ${ }^{(2,3)}$.

Stem cells originating from dental origin such as; permanent dental pulp stem cells (DPSCs), periodontal ligament stem cells (PDLSC), stem cells from human exofoliated decidious teeth (SHEDs), apical papilla stem cells (SCAPs) express several markers including the mesenchymal and bone marrow stem cell markers STRO-1 and CD146 as well as the embryonic stem cell marker, Oct4 ${ }^{(4)}$.

\section{DPSCs:}

The postnatal dental pulp includes variety of Stem cells, which play important role in dental regeneration and pulp tissue engineering. DPSCs are heterogenous and contain more than one stem cell population. Among these populations, two different stem cell populations were identified; one originating from the neural crest (ectomesenchyme) and the other arising from mesenchymal origin. DPSCs markers of neural crest origin include STRO1, CD29, CD44, CD73, CD90, CD105, CD146, CD166 and CD271. DPSCs demonstrated their osteogenic, dentinogenic, adipogenic, neurogenic, chondrogenic and myogenic differentiation capabilities when cultured with various differentiation media ${ }^{(5,4)}$

\section{Odontoblasts like cells:}

Odontoblast- like cells can be obtained from human or experimental animals originated from dental or non dental origin ${ }^{(6)}$. These cells can synthesize proteins typical to that produced from odontoblasts which are associated to dentine matrix protein synthesis and alkaline phosphatase (ALP) activity.

Odontoblast-like cell has been introduced in dental markets in order to detect cytotoxicity of dental materials products ${ }^{(6)}$. In vitro study models of odontoblast-like cell lines were developed to mimic the reparative secretory function of odontoblasts in vivo ${ }^{(6)}$

\section{Dentinogenesis}

Dentinogensis takes place by two steps. it begins with the formation of the organic predentin and followed by its subsequent mineralization. This organic matrix has a mineralization - regulatory capacity ${ }^{(7)}$.

Collagen represents about $90 \%$ of the dentin matrix protein(DMP) where collagen molecules are arranged into fibers. These fibers form collagenous network in which the mineral crystals are deposited $^{(\boldsymbol{8})}$.

ALP activity is increased as odontoblasts continue their differentiation. Odontoblasts secrete many non collagenous proteins (NCP) including dentin sialophosphoprotein (DSPP) and dentin matrix protein-1 (DMP-1) ${ }^{(9)}$. The differentiation of odontoblasts in all these cultures has been characterize the expression of extracellular matrix components such as DSPP, Collagen 1 and various NCPs such as osteocalcin (OC) and DMP-1. ${ }^{(10)}$. Many of the NCPs of dentin are also found in the bone. However, dentin is characterized by the presence of two dentin-specific NCPs, dentin sialoprotein (DSP) and dentin phosphoprotein (DPP) ${ }^{(10)}$. 
Experession of high level of DSPP is specific to odontoblasts and DSPP is detected by RT-PCR (real- time polymerase chain reaction), ${ }^{(11)}$.

DMP-1 regulates DSPP gene transcription during early odontoblast differentiation ${ }^{(12)}$. DMP-1 has two functions, it induces odontoblastic differentiation and plays a vital role in biomineralization ${ }^{(13)}$. DMP1 has a potent binding capacity to collagen fibrils and calcium. absence of DMP-1 gene shows a postnatal failure of maturation of predentin into dentin and could lead to human dentinogenesis imperfecta. Altogether this demonstrates that DMP-1 is essential for the late dentinogenesis development especially during the postnatal period ${ }^{(14,11)}$.

ALP is found in organic matrix, associated with matrix vesicles and occurring free within matrix. ALP is considered an important tool for odontoblast differentiation and dentin biomineralization ALP stimulates mineralization by supplying phosphate and permitting crystal growth to continue.

\section{MATERIAL AND METHODS}

This work was performed in the Unit of Biochemistry and Molecular Biology at The Medical Biochemistry Department, Faculty of Medicine, Cairo University.

\section{Sample collection:}

Twenty impacted human third molar teeth indicated for extraction were collected from patients from Oral Surgery department, Faculty of Oral and Dental Medicine.

Teeth surfaces were cleaned with Alcohol, put into falcon tubes containing Dulbecco Phosphate Buffer Saline (Biowest, USA) and transferred to the laborator. pulp was removed from sample by using sterile endodontic barbed broach and put quickly into another falcon tube containing Dulbecco phosphate buffer saline (Biowest, USA).

\section{DPSCs isolation and culture:}

Collagenase type II (Sigma Aldrich, USA) is used to digest the pulp tissues for 1 hour at $37^{\circ} \mathrm{C}$ in $\mathrm{CO} 2$ incubator and shacked well for every 10 minutes intervals until the tissues are fully digested.

The samples were then put into centrifuge (Sigma Aldrich, USA) for ten minutes at $3000 \mathrm{rpm}$ at room temperature to obtain pellets of isolated cells, supernatant fluid was discarded and the cells suspension was added by the use successive pipetting to culture media RPMI 1640 (Biowest, USA) using cell strainer (Bio Basic Inc., Canada) stopping the digestive action of collagenase then cells were seeded in tissue culture flasks $75 \mathrm{~cm} 3$ for cell propagation. The isolated dental pulp cells were then cultured in Dulbeco Minimum Essential Medium (DMEM). Pen Strep solution (10000U Penicillin $\mathrm{m} / \mathrm{l}$ and 10000U Streptomycin $\mathrm{m} / \mathrm{l}$ ) (Lonza, USA) and fetal bovine serum were added to the culture to achieve antibiotic effect.

\section{Identification of DPSCs}

Flow cytometeric analysis is used for expression of CD105 and CD45 surface markers.2.2.

\section{DPSCs proliferation process and passaging:}

Sub-culturing and passaging was done when adherent cells primary culture (passage zero) have reached $80 \%$ confluence.

DPSCs were then passaged into three passages. Differentiation of human dental pulp cells into odontoblast-like cells was done at the 3rd passage culture of the human dental pulp cells.

\section{Odontogenic differentiation:}

Odontogenic differentiation was induced by incubating the confluent monolayers with DMEM supplemented with $10 \%$ FBS and $50 \mu \mathrm{g} / \mathrm{ml}$ of Lascorbic acid 2-phosphate (Wako Pure Chemical Industries, Ltd, Osaka, Japan). The media was changed twice a week. 
Cell number and viability test: At day 7 and day 14 after being stained with trypan blue using a hemacytometer for examination by inverted phase contrast light microscope.

\section{Confirmation of odontogenic differentiation of DPSCs:}

\section{A) Alizarin Red Staining:}

Alizarin Red stain was used in a biochemical assay to determine the presence of calcific deposits inside and outside the cells of an odontogenic lineage. the mineralized nodules were stained and monitored using an inverted phase contrast light microscope and digital micrographs were taken at day 7 and 14 .

\section{B) Real-time reverse transcription polymerase chain reaction Quantitative $(R T-P C R)$ :}

At day 7 and day 14, RT-PCR was performed to analyze the mRNA level of odontoblastic differentiation markers which are dentin sialophosphoprotein (DSPP), ALP AND DMP1. RT-PCR amplification was performed using DSPP, ALP AND DMP1 primers using Light Cycler (Table 1) ${ }^{(15)}$.

\section{Statistical analysis:}

Data were coded and entered using the statistical package SPSS (Statistical Package for the Social Sciences) version 23. Data was summarized using mean, standard deviation. P-v less than 0.05 were considered as statistically significant.
TABLE (1) Showing primer sequences real-time reverse transcription polymerase chain reaction.

\begin{tabular}{|l|l|}
\hline Primer & $\begin{array}{l}\text { Gene Sequence } \\
5, \quad 3\end{array}$ \\
\hline ALP F: & CACTGCGGACCATTCCCACGTCTT \\
\hline ALP R: & GCGCCTGGTAGTTGTTGTGAGCATA \\
\hline DSPP F: & CAACCATAGAGAAAGCAAACGCG \\
\hline DSPP R: & TTTCTGTTGCCACTGCTGGGAC \\
\hline DMP1-F & GCATCAGGTGGCCAAAGTAT \\
\hline DMP1-R & GAAATCCCATGCAACGTTCT \\
\hline
\end{tabular}

\section{RESULTS}

Human dental pulp cells were successfully isolated from the pulp of the human teeth. Following the isolation and culturing procedures. The cells appeared with various morphologies, some spindle like, others appeared satellite-saped.

\section{Flow cytometric analysis:}

Using flow cytometric analysis, the expression of CD105and CD 45 were quantified after isolation. The flow cytometric analysis revealed $90 \%$ expression of CD10590 and $0.01 \%$ expression of CD45 (Fig.1).

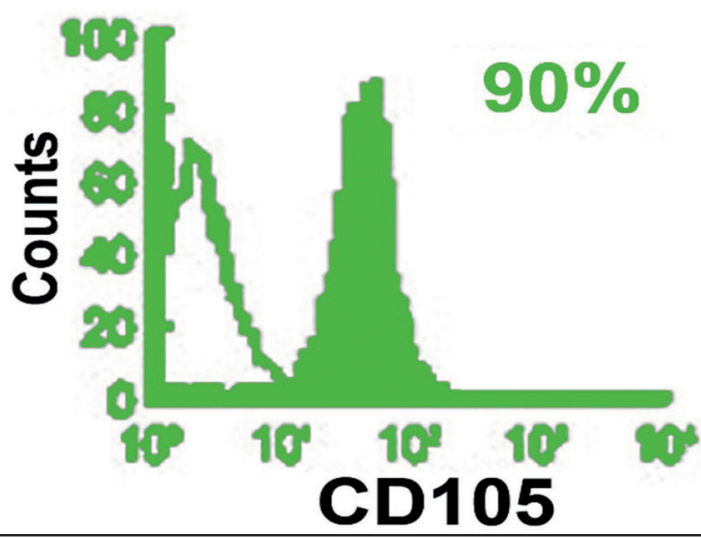

Fig. (1) Flow cytometric analysis showing CD45 with $0.01 \%$ expression and CD 105 with 90\% expression in DPSCs. 


\section{Cell Viability and Count Results}

Inverted Phase Contrast Microscope showed negative trypan blue stained rounded cells using hemacytometer indicating cell viability, while positive stained indicated the dead cells as in. Cell count at 7 days is higher than at 14 days.(table2)

TABLE (2): Showing the average mean values of cell count per flask in each group.

\begin{tabular}{|c|c|}
\hline \multicolumn{2}{|c|}{ CELL COUNT } \\
\hline At 7 days after differention & At 14 days after differention \\
\hline 444,000 & 380,000 \\
\hline
\end{tabular}

\section{Alizarin Red Staining}

On the 7 th and 14th days after odontogenic differentiation, cultured cells were stained with Alizarin Red stain to identify nodules of calcification. Cultured cells gave positive results indicating the formation of calcific deposits at the seventh day, (Fig.2). By the14th day, the staining became more intense and multiple mineralized sites appeared inside cells and at the cells boundary (Fig3 ).

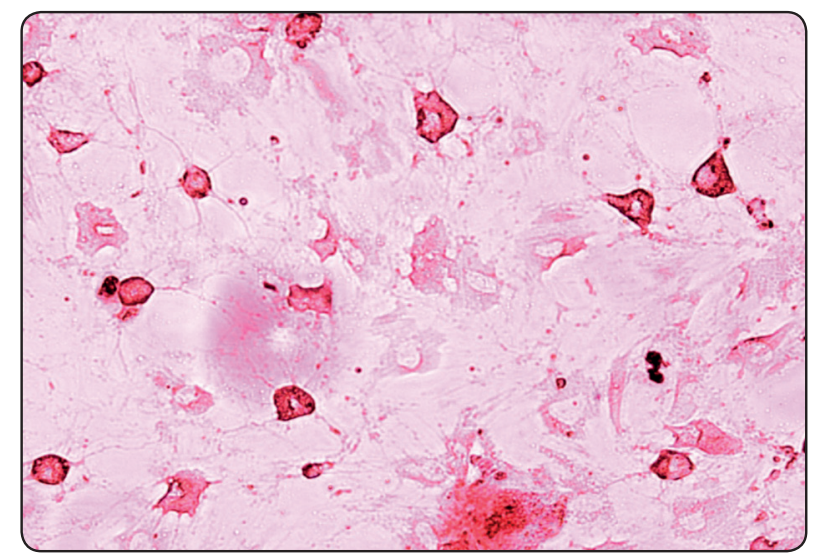

Fig. (2) Photomicrograph showing differentiated dental pulp cells (day 7) stained with Alizarin Red (Original magnification $\mathrm{x} 400$ ) showing calcific deposits on its cell borders.

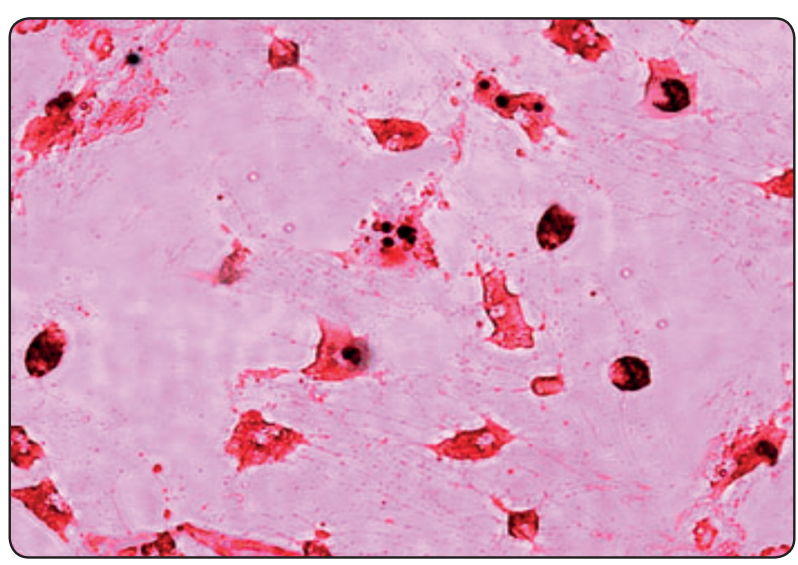

Fig. (3) Photomicrograph of differentiated dental pulp cells at 14 days stained with Alizarin Red (Original magnification $x$ 400) showing increase calcific deposits inside the cells and at the cell boundary.

Quantitative RT-PCR revealed that the expression of DSPP, BMP1 and ALP mRNAs was increased in the 14 th day. (Tables :3,4,5). Figs $(4,5,6)$

DSPP:

TABLE (3) The mean, standard deviation (SD) values of DSPP after 2 weeks and 3 weeks.

\begin{tabular}{|c|c|}
\hline Variables & Mean \pm SD \\
\hline 7 days & $0.302 \pm 0.093$ \\
\hline 21 days & $0.578 \pm 0.198$ \\
\hline P-value & $0.001 *$ \\
\hline
\end{tabular}

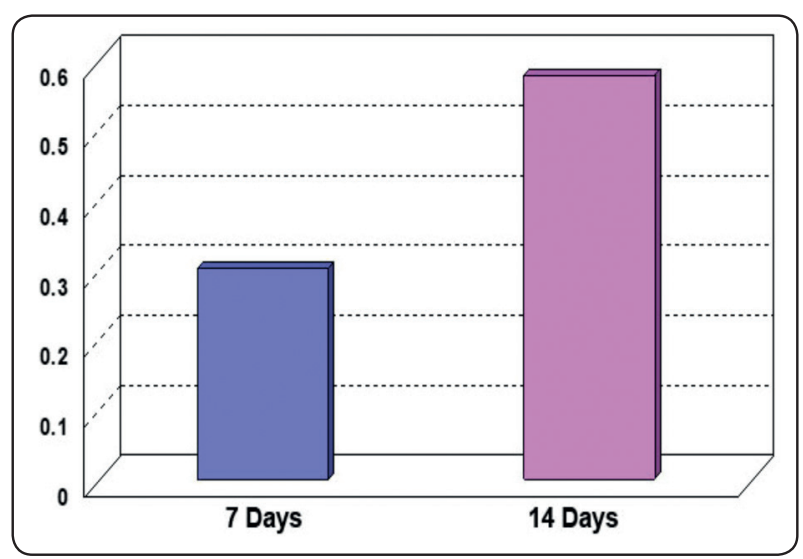

Fig. (4): Showing increase the expression of DSPP at day 14. 


\section{DMP1 Results}

TABLE (4) The mean, standard deviation (SD) values of DMP1 after 2 weeks and 3 weeks

\begin{tabular}{|c|c|}
\hline Variables & Mean \pm SD \\
\hline $\mathbf{7}$ days & $68556.58 \pm 2231.82$ \\
\hline 14 days & $106239.80 \pm 23781.67$ \\
\hline $\boldsymbol{P}$-value & $\mathbf{0 . 0 0 1 *}$ \\
\hline
\end{tabular}

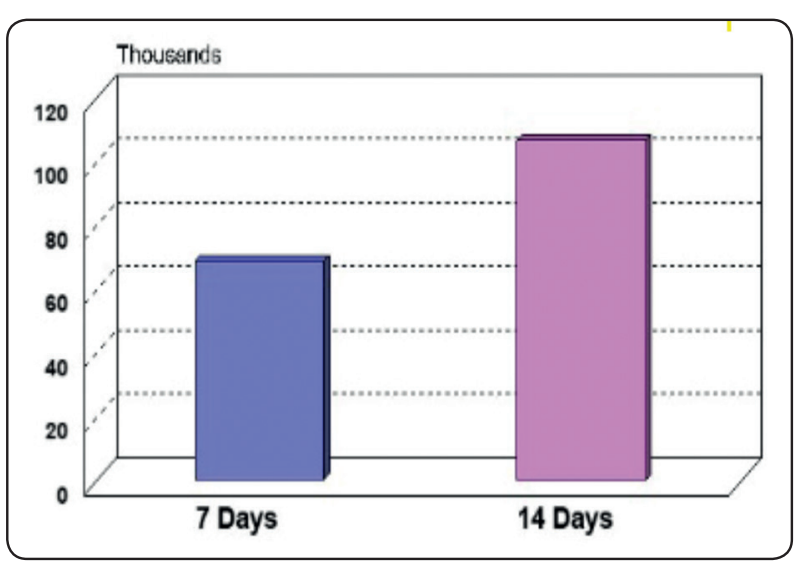

Fig. (5) showing increase expression of DMPI at day 14

\section{ALP Results}

TABLE (5) The mean, standard deviation (SD) values of ALP after 2 weeks and 3 weeks

\begin{tabular}{|c|c|}
\hline Variables & Mean \pm SD \\
\hline $\mathbf{7}$ days & $1321076.80 \pm 100025.00$ \\
\hline $\mathbf{1 4}$ days & $1373070.50 \pm 100003.50$ \\
\hline P-value & $\mathbf{0 . 0 0 1 *}$ \\
\hline
\end{tabular}

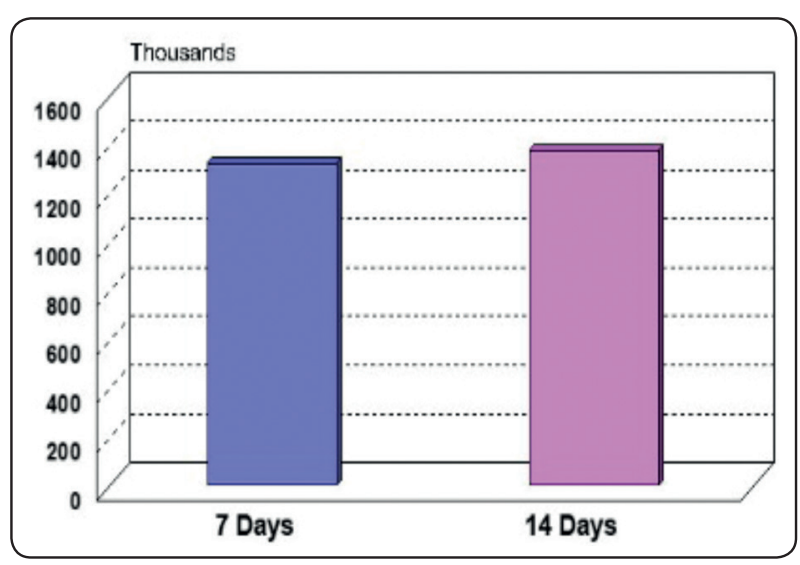

Fig.(6): Showing increase expression of ALP at day 14.

\section{DISCUSSION}

Regenerative ability of stem cells may offer an alternative method to save teeth that may have compromised structural integrity ${ }^{(16)}$. Stem cells can be a possible source of stable differentiated cells. Stem cells have increased the attention of researchers because of their ability of inducing hard tissue formation ${ }^{(17)}$.

The fact that dental pulp stem cell can differentiate into dentin-forming cells has been investigated by many studies.

The isolation of dental pulp stem cells from tissue of origin and the process of proliferating them in vitro prior to transplanting them have been proved to give the cells a more accessible area to secrete extracellular matrix and initiate the differentiation of odontoblast-like cells ${ }^{(18)}$.

In in vivo studies, the close proximity of cells in varying stages of differentiation makes it difficult to understand the molecular mechanisms of odontoblast differentiation In mice(animal model), the steps between the formation of preodontoblasts and mature odontoblasts occur fast and are completed within 6-10 hours ${ }^{(19)}$.

The differentiation of odontoblasts from cultured stem cells of dental and non-dental origin has made odontoblast-like cells a valuable model for 
examining the mechanisms regulating the sequential steps involved in odontoblast differentiation ${ }^{(20,11)}$.

In the current study, isolated DPSCs were identified by positive expression of CD 105 and and negative expression of hematopoietic marker CD45.

Cell viability was examined daily by inverted phase contrast light microscope. This test was done daily to check viability of the cells during cell subculturing. ${ }^{(21)}$

In the present study, the protocol used to induce odontoblast-like cells from DPSCs was based on the work of other researchers who used rat DPSCs cell line to introduce odontoblast-like cells. ${ }^{(15)}$

In the present study, the formation of mineralized structures in vitro was evident following the addition of differentiation chemicals such as ascorbic acid, Dexamethasone, and $\beta$-glycerophosphate in accordance with previous study ${ }^{(28)}$.

Variable durations used in the present study,7 and 14 days after odontoblastic differentiation were selected in order to detect the changes that occur in odontoblast-like cells upon odontoblastic differentiation and its further proliferation. The suggested duration was selected in accordance with the other authors who examined the odontogenic potential of mouse undifferentiated pulp cells in vitro after 3, 7, 10 and 14 days from culture. ${ }^{(22)}$.

To confirm odontoblastic differentiation from DPSCs results in the present study was obtained by Alizarin red stain and by RT-PCR tests for DMP1, ALP and DSPP genes expression.

In the current study, Alizarin red was used stain to confirm mineralized nodule formation. It was very clear that was represented by the positive red stained nodules. This agrees with the previous work done by other authors who used Alizarin red stain to confirm odontogenic differentiation of dental pulp stem cells ${ }^{[8]}$.

In the present study, Mineralized matrix formation stained by alizarin red was more advanced at 14 days after odontoblastic differentiation than at 7 days which coincides with the results of previous investigators ${ }^{(23)}$. This results could be correlated to the increase of DMP1 level found in this study at 14 days of differentiation as DMP1 plays a vital role in biomineralization ${ }^{(13,24)}$. The positive verification results of the present study coincided with many researches who defined DSPP as a more specific gene indicating complete odontoblastic differentiation $^{(15,3)}$.

DMP-1 gene expression using RT-PCR test was selected in the present study as it was reported that DMP-1 regulates DSPP gene transcription during early odontoblast differentiation (Narayanan et al., 2006). It is important in the nucleation, transformation, and growth of hydroxyapatite crystals (24). DMP-1 is also essential for the late dentinogenesis development ${ }^{(11)}$.

ALP gene expression using RT-PCR test was selected in the present study as it is reported that ALP stimulates dentin matrix formation, mineralization It is also observed a correlation between the high levels of ALP and an increase in mineralized globules through Alizarin red stain ${ }^{(22)}$.

In the current study, cell count regarding time, were increased after 7 days of odontoblastic differentiation than after 14 days of odontoblastic differentiation. this indicates that cell count and viability of the present study was more as early differentiation than at later stages.the decrease in cell count at day 14 might be correlated to the reduction of cell growth after odontoblastic differentiation ${ }^{(25)}$.

Statistical results of DMP1 gene expression of the present study regarding time of examination were increased after 14 days of odontoblastic differentiation which coincides with the studies of previous investigators who reported increase the expression of DMP1 at later stages of dentinogenesis ${ }^{(26,22,27)}$. DMP1 plays an important 
role in biomineralization, regulation of phosphate homeostasis and cell differentiation and is present extracellularly around the mineralizing globules $^{(13,24,11)}$.

Statistical results of ALP gene expression results of the present study were increased at day 14 from odontoblastic differentiation .Our result was coincided other investigators Semeghini et al., 2012 where ALP gene expression was increased by increasing duration after odontoblastic differentiation. The late increase in ALP expression is due to the increase in extracellular matrix mineralization globules at later stages. ${ }^{(28,15,28,29)}$.

A correlation between the high levels of ALP and an increase in mineralized nodule was observed through alizarin red staining in odontoblast like cells ${ }^{(22)}$.

However Our results are not in accordance with other researchers who reported that the increase in ALP activity at early odontoblastic differentiation is attributed to its property to be one of the markers of odontoblastic differentiation and this is followed by decrease in ALP expression later stages when mineralization become advanced. ${ }^{(25)}$

According to the obtained results in the current investigation, it could be concluded that can be isolated and possess an Odontogenic potential as they could be differentiated into odontoblasts like cells and could produce mineralized nodules, when cultured in the proper odontogenic medium. This was supported by alizarin red staining results and by RTPCR examination for the expression of DSPP, ALP and DMP1 genes.

The future of use of stem cells in dentistry is great, but there are major challenges that must be met in the following years for this new field to reach its potential application. Some of the main challenges lie not in the scientific side, but in the application of the technology.

\section{REFERENCES}

1. Demarco FF, Marcus Conde CM, Cavalcanti BN, Casagrande L, Sakai VT, Nor JE. Dental Pulp Tissue Engineering. Braz Dent J. 2011; 22(1): 3-14.

2. Malhotra N and Mala K (2012). Regenerative endodontics as a tissue engineering approach: Past, current and future. Aust Endod J 38: 137-148.

3. Abbas FM, Fallahi HS, Khoshzaban A, Mahdavi N and Bagheri SS (2013). Expression of odontogenic genes in human bone marrow mesenchymal stem cells. Cell Journal 15(2): 136-141.

4. Jamal M, Chogle S, Goodis H and Karam SM (2011). Dental Stem Cells and Their Potential Role in Regenerative. Journal of Medical Sciences 4(2): 53-61.

5. Zhang W, Walboomers XF, Shi S, Fan M and Jansen JA (2006). Multilineage differentiation potential of stem cells derived from human dental pulp after cryopreservation. Tissue Eng 12: 2813-23.

6. Lima AF, Basso FG, Ribeiro APD, Bagnato VS, Hebling J, Marchi GM and de Souza Costa CA (2014). Effects of Laser Irradiation on Pulp Cells Exposed to Bleaching Agents . Photochemistry and Photobiology 90: 201-206.

7. Almushayt A, Narayanan K, Zaki AE and George A (2006). Dentin matrix protein 1 induces cytodifferentiation of dental pulp stem cells into odontoblasts. Gene therapy 13: 611-20.

8. Yasuda Y, Ohtomo E, Tsukuba T, Okamoto K and SaitoT (2009). Carbon dioxide laser irradiation stimulates mineralization in rat dental pulp cells. International Endodontic Journal 42: 940-946.

9. Bjorndal L, Reit C, Bruun G, Markvart M, Kjaeldgaard M, Nasman P, Thordrup M, Dige I, Nyvad B, Fransson H, Lager A, Ericson D, Petersson K, Olsson J, Santimano EM, Wennström A, Winkel P, Gluud C (2010). Treatment of deep caries lesions inadults: randomized clinical trials comparing stepwise vs. direct complete excavation, and direct pulp capping vs. partial pulpotomy. Eur J Oral Sci 118(3): 290-7.

10. Rutherford RB, Spangberg L, Tucker M, Rueger D, Charrette M (1994). The time-course of the induction of reparative dentine formation by recombinant human osteogenic protein-1. Arch Oral Biol 39: 833-8.

11. Goldberg M (2014). The Dental Pulp Biology, Pathology, and Regenerative Therapies. Springer. Berlin, Heidelberg. 
12. Narayanan K, Gajjeraman S, Ramachandran A, Hao J and George A (2006). Dentin Matrix Protein 1 Regulates Dentin Sialophosphoprotein Gene Transcription during Early Odontoblast Differentiation. J. Biol. Chem. 281:1906419071.

13. Orsini G, Ruggeri A, Mazzoni A, Nato F, Manzoli L, Putignano A, Di Lenarda R, Tjäderhane L and Breschi L (2012). A review of the nature, role and function of dentin non-collagenous proteins. Part 1: proteoglycans and glycoproteins. Endodontic Topics 21: 1-18.

14. Ye L, MacDougall M, Zhang S, Xie Y, Zhang J, Li Z, Lu Y, Mishina Y and Feng JQ (2004). Deletion of dentin matrix protein-1 leads to a partial failure of maturation of predentin into dentin, hypomineralization, and expanded cavities of pulp and root canal during postnatal tooth development. J Biol Chem 279: 19141-8.

15. Magne D, Bluteau G, Lopez-Cazaux S, Weiss P, Pilet P, Ritchie HH, Daculsi G and Guicheux J (2004). Development of an odontoblast in vitro model to study dentin mineralization.Connective Tissue Research 45(2): 101-8.

16. Nakashima M, Iohara K, Ishikawa M, Ito M, Tomokiyo A, Tanaka T, Akamine A. Stimulation of reparative dentin formation by ex vivo gene therapy using dental pulp stem cells electrotransfected with growth/differentiation factor 11 (Gdf11). Human Gene Therapy. 2004;15:1045-1053.

17. Murray PE, Godoy FG, Hargreaves KM. Regenerative endodontics: A review of current status and a call for action. Journal of Endodontics. 2007;33(4):377-390.

18. Ohazama A, Modina SA, Miletich I, Sharpe PT. Stemcell based tissue engineering of marine teeth. J Dent Res. 2004; 83:518-522.

19. Lesot H, Lisi S, Peterkova R, Peterka M, Mitolo V and Ruch JV (2001). Epigenetic signals during odontoblast differentiation. Adv Dent Res 15:8-13.

20. Lei G, Yu Y, Jiang Y, Wang S, Yan M, Smith AJ, Smith G, Cooper PR, Tang C, Zhang G and Yu J (2013). Differentiation of BMMSCs into odontoblast-like cells induced by natural dentine matrix.Journal Arch Oral Biol 58(7): 862-70.
21. De Ugarte DA, Alfonso Z, Zuk PA, Elbarbary A, Zhu M, Ashjian P, Benhaim P, Hedrick MH and Fraser JK (2003). Differential expression of stem cell mobilization-associated molecules on multilineage cells from adipose tissue and bone marrow. Immunology letters 89: 267-70.

22. Semeghini MS,Fernandes RR, Chimello DT, de Oliveira FS and Bombonato-Prado KF (2012). In Vitro Evaluation of the Odontogenic Potential of Mouse Undifferentiated Pulp Cells. Braz Dent J 23(4): 328-336.

23. Mohamed MS, Hakam HM and Korany NS (2010). Expression of mineralization markers in isolated postnatal human dental pulp stem cells in diabetic patients (An in vitro study). Master degree thesis. Cairo University. Egypt.

24. Tjäderhane L and Haapasalo M (2012). The dentin-pulp border: a dynamic interface between hard and soft tissues. Endodontic Topics 20: 52-84.

25. Nakasone N, Yoshie H and Ohshima H (2006). An immune-histochemical study of the expression of heat-shock protein- 25 and cell proliferation in the dental pulp and enamel organ during odontogenesis in rat molars. Arch Oral Biol 51:378-386.

26. Lacerda-Pinheiro S, Dimitrova-Nakov S, Harichane Y, Souyri M, Petit Cocault L, Legrès L, Marchadier A, Baudry A, Ribes S, Goldberg M, Kellermann O and Poliard A (2012). Concomitant multipotent and unipotent dental pulp progenitors and their respective contribution to mineralised tissue formation. Eur Cell Mater 23:371-86.

27. Han N, Zheng Y, Li R, Li X, Zhou M, Zhou M, Niu Y and Zhang Q (2014). b-Catenin Enhances Odontoblastic Differentiation of Dental Pulp Cells through Activation of Runx2. PLoSONE 9(2): e88890.

28. Yokose S, Kadokura H, Tajima Y, Fujieda K, Katayama I, Matsuoka T and Katayama T (2000). Establishment and characterization of a culture system for enzymatically released rat dental pulp cells. alcif Tissue Int 66(2): 139-144.

29. Matsui S, Takeuchi H, Tsujimoto $Y$ and Matsushima K (2008). Effects of Smads and BMPs induced by Ga-Al-As laser irradiation on calcification ability of human dental pulp cells. Journal of Oral Science 50(1): 75-81. 